\title{
Review of the Refeeding Syndrome
}

\author{
Michael D. Kraft, PharmD*†; Imad F. Btaiche, PharmD, BCNSP*†; and \\ Gordon S. Sacks, PharmD, BCNSP \\ *Department of Clinical Sciences, College of Pharmacy, University of Michigan, Ann Arbor, Michigan; $\uparrow$ Department of \\ Pharmacy Services, University of Michigan Health System, Ann Arbor, Michigan; and the \$Pharmacy Practice \\ Division, School of Pharmacy, University of Wisconsin-Madison, Madison, Wisconsin
}

\begin{abstract}
Refeeding syndrome describes a constellation of metabolic disturbances that occur as a result of reinstitution of nutrition to patients who are starved or severely malnourished. Patients can develop fluid and electrolyte disorders, especially hypophosphatemia, along with neurologic, pulmonary, cardiac, neuromuscular, and hematologic complications. We reviewed literature on refeeding syndrome and the associated electrolyte abnormalities, fluid disturbances, and associated complications. In addition to assessing scientific literature, we also considered clinical experience and judgment in developing recommendations for prevention and treatment of refeeding syndrome. The most important steps are to identify patients at risk for developing refeeding syndrome, institute nutrition support cautiously, and correct and supplement electrolyte and vitamin deficiencies to avoid refeeding syndrome. We provide suggestions for the prevention of refeeding syndrome and suggestions for treatment of electrolyte disturbances and complications in patients who develop refeeding syndrome, according to evidence in the literature, the pathophysiology of refeeding syndrome, and clinical experience and judgment.
\end{abstract}

The term refeeding syndrome (RS) is generally reserved to describe the metabolic alterations that occur during nutrition repletion of underweight, severely malnourished, or starved individuals. The hallmark sign of RS is severe hypophosphatemia and its associated complications. However, RS actually encompasses a constellation of fluid and electrolyte abnormalities affecting multiple organ systems, including neurologic, cardiac, hematologic, neuro-

Correspondence: Michael D. Kraft, PharmD, Clinical Assistant Professor and Clinical Pharmacist, University of Michigan Health System, Department of Pharmacy Services, UH/B2 D301, Box 0008, 1500 East Medical Center Drive, Ann Arbor, MI 48109-0008. Electronic mail may be sent to mdkraft@umich.edu.

0884-5336/05/2006-0625\$03.00/0

Nutrition in Clinical Practice 20:625-633, December 2005

Copyright $\odot 2005$ American Society for Parenteral and Enteral Nutrition muscular, and pulmonary function. This article will review the pathophysiology of RS, its physiologic complications, the treatment of associated metabolic disturbances, and provide guidelines for its recognition and prevention.

The classic study describing RS was conducted by Keys and colleagues ${ }^{1}$ in 1944 on male conscientious objectors of World War II. The participants had undergone semistarvation for 6 months and upon nutrition replenishment, some subjects developed cardiac failure. With the advent of modern-day parenteral nutrition $(\mathrm{PN})$ and enteral nutrition ( $\mathrm{EN})$, reports of similar complications were noted in severely undernourished patients who received aggressive nutrition supplementation. Weinsier and Krumdieck $^{2}$ reported cardiopulmonary failure resulting in death of 2 chronically undernourished women who received aggressive PN. Both patients were well below ideal body weight (IBW; $40 \%$ and $70 \%$, respectively) and exhibited low serum concentrations of potassium and phosphorus before PN initiation. Large amounts of carbohydrate and protein were delivered (approximately $75 \mathrm{kcal} / \mathrm{kg}$ from dextrose and $3.5 \mathrm{~g} / \mathrm{kg}$ of protein) at $\mathrm{PN}$ initiation, rather than gradually increasing $\mathrm{PN}$ calories to goal over the following days. Within 48 hours, both patients experienced cardiac abnormalities and pulmonary failure requiring mechanical ventilation. Severe hypophosphatemia, hypokalemia, and hypomagnesemia occurred despite the presence of supplemental electrolytes in the PN formulations. One patient died on hospital day 6 and the other died during the third week of hospitalization. These outcomes represent the most severe responses to refeeding but underscore the importance of understanding this syndrome, recognizing patients at risk, and providing appropriate treatment in the event of its occurrence.

\section{Overview of Refeeding Syndrome}

\section{Starvation}

Understanding the physiology of starvation provides insight into the morbid sequelae associated with refeeding a severely undernourished individ- 
ual. During the initial period of starvation (24-72 hours), the liver uses glycogen stores for energy and skeletal muscle to provide amino acids as a source for new glucose production (ie, gluconeogenesis) for glucose-dependent tissues, such as the brain, renal medulla, and red blood cells. After 72 hours of starvation, metabolic pathways shift to derive energy from ketone production as a result of free fatty acid oxidation while sparing protein mobilization from skeletal muscle. ${ }^{3}$ Other adaptive mechanisms include an overall decrease in liver gluconeogenesis, a decline in basal metabolic rate, reduction in the secretion of insulin, and an increased use of free fatty acids by the brain as the primary energy source in place of glucose.

\section{Refeeding}

With the reintroduction of carbohydrate via oral feeding, EN, or PN, there is a sudden shift back to glucose as the predominant fuel source, creating a high demand for the production of phosphorylated intermediates of glycolysis (ie, red blood cell adenosine triphosphate [ATP] and 2,3-diphosphoglycerate [DPG]) with inhibition of fat metabolism. This results in hypophosphatemia, the hallmark sign of RS. Additional mechanisms identified as contributing to low serum phosphorus concentrations include preexisting low total body stores of phosphorus during starvation and enhanced cellular uptake of phosphorus during anabolic refeeding. Phosphate is necessary for accrual of lean tissue mass and is a vital component of metabolic pathways involving the production of ATP and 2,3-DPG. Potassium and magnesium also shift intracellularly in response to anabolism and increased insulin release. Magnesium is a cofactor for the Na- $\mathrm{K}^{+}$ATPase pump, so uncorrected hypomagnesemia can complicate potassium repletion. Other metabolic alterations that may occur include fluid imbalance and vitamin deficiencies. An expansion of the extracellular water compartment occurs during refeeding of the malnourished individual. Although the exact mechanism of fluid imbalance in RS is unknown, sodium and water retention may be due to an antinatriuretic effect from hyperinsulinemia ${ }^{4}$ or a possible interaction between the water, sodium, and carbohydrate homeostasis. ${ }^{5}$ Although it is difficult to determine whether thiamine deficiency is a result of $\mathrm{RS}$ or is a preexisting deficiency due to starvation, it is reasonable to presume that an undernourished individual is at risk for thiamine deficiency. Thiamine is an essential cofactor involved in the metabolism of carbohydrates. ${ }^{6}$ The phosphorylated form of glucose is converted to pyruvate, which undergoes decarboxylation in the presence of pyruvate dehydrogenase and thiamine. Acetyl coenzyme A is produced for entrance into the Krebs cycle and generation of ATP as an energy source for all living cells. High doses of carbohydrate can increase the demand for thiamine use in undernourished subjects with decreased baseline thiamine stores, thus precipitating thiamine deficiency and its associated complications. ${ }^{6}$ As a result, thiamine administration prior to and during carbohydrate intake is recommended in patients at risk for RS.

\section{Clinical Manifestations}

Clinical manifestations of RS are related to the electrolyte and vitamin deficiencies that are present and the subsequent abnormalities that develop with the initiation of nutrition support. Clinical manifestations of RS are summarized in Table 1.

\section{Hypophosphatemia}

Phosphorus is the major intracellular anion, and it is important for many metabolic processes involving ATP and 2,3-DPG as described previously. Severe hypophosphatemia (eg, serum phosphorus concentration $<1-1.5 \mathrm{mg} / \mathrm{dL}$ ) can lead to severe neurologic, cardiac, respiratory, and hematologic abnormalities and possibly death. Several reports describe hypophosphatemia associated with the initiation of nutrition support (oral, enteral, and parenteral). ${ }^{2,7-15}$ Severe hypophosphatemia in these patients has also led to neurologic symptoms, including paresthesias, weakness, confusion, disorientation, encephalopathy, areflexic paralysis, seizures, coma, and death. ${ }^{8-10,12,13,16,17}$ Silvas and Paragas $^{8}$ described RS in 3 patients with severe malnutrition who received aggressive $\mathrm{PN}$ for repletion. All 3 adult patients were significantly underweight $(\sim 50 \%-60 \%$ of usual body weight, or reported weight loss of approximately $22-30 \mathrm{~kg}$ [50-65 pounds]); $\mathrm{PN}$ was initiated at a high rate ( $\sim 37-40 \mathrm{kcal} / \mathrm{kg} /$ day on day 1$)$, and advanced rapidly over the course of $2-5$ days (up to $\sim 65-100$ $\mathrm{kcal} / \mathrm{kg} /$ day). Patients developed paresthesias, weakness, somnolence, lethargy, restlessness, and muscle aches around day 5 of PN. Two patients became unresponsive, developed seizures (on days 8 and 16 of PN) and coma; 1 patient expired 5 days after the initial seizure (4 days after PN was discontinued). Serum phosphorus concentrations decreased over the first 5-8 days and reached a nadir of $0.1-0.5 \mathrm{mg} / \mathrm{dL}$. Of note, 2 of the patients gained approximately $1.8 \mathrm{~kg}$ (4 pounds) relatively quickly after initiation of $\mathrm{PN}$, likely reflecting fluid retention.

Severe hypophosphatemia has also been show to impair cardiac function ${ }^{18}$ and respiratory function. ${ }^{14,19,20}$ O'Connor et al $^{18}$ described diminished cardiac function in patients with serum phosphorus concentrations of $0.7-1.4 \mathrm{mg} / \mathrm{dL}$. Stroke volume (SV), mean arterial pressure (MAP), and left ventricular stroke work (LVSW) were all decreased and pulmonary artery wedge pressure (PAWP) was increased. SV, MAP, and LVSW increased significantly, with a significant decrease in PAWP, after phosphate repletion over 8 hours (serum levels $=$ 
Table 1

Clinical manifestations of refeeding syndrome

\begin{tabular}{|c|c|c|c|c|}
\hline Hypophosphatemia & Hypokalemia & Hypomagnesemia & $\begin{array}{c}\text { Vitamin/Thiamine } \\
\text { Deficiency }\end{array}$ & Sodium Retention \\
\hline $\begin{array}{l}\text { Impaired oxygen transport } \\
\text { and delivery, hypoxia } \\
\text { Impaired cardiac function } \\
\text { Impaired diaphragm } \\
\text { contractility } \\
\text { Respiratory failure } \\
\text { Paresthesias } \\
\text { Weakness } \\
\text { Lethargy } \\
\text { Somnolence } \\
\text { Confusion } \\
\text { Disorientation } \\
\text { Restlessness } \\
\text { Encephalopathy } \\
\text { Areflexic paralysis } \\
\text { Seizures } \\
\text { Coma } \\
\text { Death }\end{array}$ & $\begin{array}{l}\text { Nausea } \\
\text { Vomiting } \\
\text { Constipation } \\
\text { Weakness } \\
\text { Paralysis } \\
\text { Respiratory compromise } \\
\text { Rhabdomyolysis } \\
\text { Muscle necrosis } \\
\text { Alterations in myocardial } \\
\text { contraction } \\
\text { Electrocardiograph changes } \\
\text { ST-segment depression } \\
\text { T-wave flattening } \\
\text { T-wave inversion } \\
\text { Presence of U-waves } \\
\text { Cardiac arrhythmias } \\
\text { Atrial tachycardia } \\
\text { Bradycardia } \\
\text { Atrioventricular block } \\
\text { Premature ventricular } \\
\text { contractions } \\
\text { Ventricular tachycardia } \\
\text { Ventricular fibrillation } \\
\text { Sudden death }\end{array}$ & $\begin{array}{l}\text { Weakness } \\
\text { Muscle twitching } \\
\text { Tremor } \\
\text { Altered mental status } \\
\text { Anorexia } \\
\text { Nausea } \\
\text { Vomiting } \\
\text { Diarrhea } \\
\text { Refractory hypokalemia and } \\
\text { hypocalcemia } \\
\text { Electrocardiograph changes } \\
\text { Prolonged PR } \\
\text { Widened QRS } \\
\text { Prolonged QT } \\
\text { ST depression } \\
\text { Peaked T-wave } \\
\text { T-wave flattening } \\
\text { Cardiac arrhythmias } \\
\text { Atrial fibrillation } \\
\text { Torsade de pointes } \\
\text { Ventricular arrhythmias } \\
\text { Ventricular tachycardia } \\
\text { Tetany } \\
\text { Convulsions } \\
\text { Seizures } \\
\text { Coma } \\
\text { Death }\end{array}$ & $\begin{array}{l}\text { Encephalopathy leg, } \\
\text { Wernicke-Korsakoff } \\
\text { encephalopathy) } \\
\text { Lactic acidosis } \\
\text { Death }\end{array}$ & $\begin{array}{l}\text { Fluid overload } \\
\text { Pulmonary edema } \\
\text { Cardiac decompensation }\end{array}$ \\
\hline
\end{tabular}

$1.6-4.7 \mathrm{mg} / \mathrm{dL})$. Severe hypophosphatemia has also been shown to impair diaphragmatic contractility ${ }^{20}$ and lead to acute respiratory failure requiring intubation and mechanical ventilation. ${ }^{14,19}$ Youssef $^{14}$ described a case of a woman with multiple intestinal fistulae who underwent a laparotomy and then began PN. She developed respiratory failure on postoperative day 2 (her second day of $\mathrm{PN}$ ) and went on to develop generalized convulsions, coma, and required intubation and mechanical ventilation.

Hypophosphatemia can lead to decreases in ATP and 2,3-DPG as described previously. This may lead to further abnormalities in oxygen transport and delivery, ${ }^{7,11,21-23}$ and impaired glucose metabolism. ${ }^{7}$ Hypophosphatemia and a subsequent decrease in 2,3-DPG increase the affinity of hemoglobin for oxygen and shifts the oxygen dissociation curve to the left. ${ }^{21-23}$ Sheldon and Grzyb ${ }^{11}$ described hypophosphatemia and associated abnormalities in a series of 19 trauma patients, 8 of whom inadvertently were given PN without phosphate supplementation. Patients who developed hypophosphatemia also had decreased levels of ATP and 2,3-DPG. The authors further found a significant correlation between total calories administered and the fall in serum phosphorus concentration, and a significant correlation between the amount of phosphate administered and the increase in serum phosphorus concentration. Travis et $\mathrm{al}^{7}$ found that within 5-7 days of PN initiation (3-4 L/day) that did not contain phosphate, 5 of 8 patients developed severe hypophosphatemia (serum phosphorus concentration $<1 \mathrm{mg} / \mathrm{dL}$, mean $=0.5 \mathrm{mg} / \mathrm{dL}$ ). Hypophos- phatemia also led to reductions in erythrocyte ATP and 2,3-DPG, with an associated increase of hemoglobin affinity for oxygen $\left(\mathrm{P}_{50}=19.5 \mathrm{~mm} \mathrm{Hg}\right.$, normal $\sim 27 \pm 1.1 \mathrm{~mm} \mathrm{Hg}$ ). Furthermore, hypophosphatemia led to significant decreases in erythrocyte glucose-6-phosphate and fructose-6-phosphate, and a significant increase in total triose phosphates (eg, glyceraldehyde-3-phosphate, dihydroxyacetone phosphate), suggesting a decrease in erythrocyte glycolysis. These decreases in oxygenation and glucose metabolism may also lead to central nervous system and respiratory symptoms, as discussed.

\section{Hypokalemia}

Potassium is the major intracellular cation, with approximately $98 \%$ of total body potassium residing in the intracellular space but also in bone and cartilage. ${ }^{24,25}$ Potassium has many important physiologic functions, including regulation of electrical cellular membrane potential, cellular metabolism, glycogen synthesis, and protein synthesis. Hypokalemia alters the electrical action potential across cell membranes and leads to membrane hyperpolarization and impaired muscular contraction. ${ }^{24-27}$ Mild to moderate hypokalemia (eg, serum potassium concentration $=2.5-3.5 \mathrm{mEq} / \mathrm{L}$ ) can cause nausea, vomiting, constipation, and weakness. If left untreated, severe hypokalemia (eg, serum potassium concentration $<2.5 \mathrm{mEq} / \mathrm{L}$ ) can lead to paralysis, respiratory compromise, rhabdomyolysis, muscle necrosis, and changes in myocardial contraction and signal conduction. ${ }^{26-29}$ Patients 
with severe hypokalemia may develop electrocardiograph changes such as ST-segment depression, T-wave flattening, T-wave inversion, or the presence of U-waves. ${ }^{26,27,29}$ Patients may also develop cardiac arrhythmias, including atrial tachycardia, bradycardia, atrioventricular block, premature ventricular contractions, ventricular tachycardia, ventricular fibrillation, and possibly sudden death. ${ }^{25-28}$

\section{Hypomagnesemia}

Magnesium is the second most abundant intracellular cation, with most of the total body magnesium found in bone, muscle, and soft tissue. ${ }^{30-32}$ Approximately $1 \%$ of the total body magnesium resides in the extracellular fluid. ${ }^{30-32}$ Magnesium is an important cofactor for many enzymes and in many biochemical reactions, including reactions during oxidative phosphorylation and those involving ATP. ${ }^{30,32,33}$

Hypomagnesemia (serum magnesium concentration $<1.5 \mathrm{mg} / \mathrm{dL}$ ) is frequently observed in critically ill patients $^{34-37}$ and has been associated with increased morbidity and mortality. ${ }^{35,36,38,39}$ Signs and symptoms of hypomagnesemia can resemble those of hypokalemia or hypophosphatemia. Patients with mild to moderate hypomagnesemia can experience weakness, muscle twitching, tremor, altered mental status, anorexia, nausea, vomiting, and diarrhea. ${ }^{30-32,35,40,41}$ Moderate to severe hypomagnesemia (eg, serum magnesium concentration $<1.0 \mathrm{mg} / \mathrm{dL}$ ) can manifest such signs and symptoms as electrocardiographic changes (eg, prolonged PR, widened QRS, prolonged QT, ST depression, peaked T-wave, or T-wave flattening), ${ }^{30-32,42}$ cardiac arrhythmias (eg, atrial fibrillation, torsade de pointes, ventricular arrhythmias, ventricular tachycardia), ${ }^{32,35,39}$ tetany, convulsions, seizures, coma, and even death. ${ }^{30-32,35,41}$ Hypomagnesemia, if left untreated, can also complicate the treatment of coexisting hypokalemia and hypocalcemia. Hypomagnesemia-induced hypokalemia is likely due to impaired $\mathrm{Na}^{+} / \mathrm{K}^{+}$-ATPase activity. ${ }^{43}$ Hypomagnesemia-induced hypocalcemia is likely a result of impaired parathyroid hormone release and/or activity. ${ }^{44-46}$

\section{Vitamin/Thiamine Deficiency}

Thiamine is an important cofactor in carbohydrate metabolism. ${ }^{6}$ Thiamine is a water-soluble vitamin, and total body stores can quickly become depleted with weight loss and malnutrition. With carbohydrate intake, there is an increased demand for thiamine, a cofactor in glycolysis. Thiamine deficiency in malnourished patients has led to Wernicke's encephalopathy in patients who were given PN with high carbohydrate loads. ${ }^{12,17,47}$ With thiamine deficiency, pyruvate is then converted to lactate. ${ }^{48}$ Excessive lactate formation leading to lactic acidosis and death was reported in patients who received PN without thiamine supplementation. ${ }^{49-52}$
The role of other vitamin deficiencies (especially water-soluble vitamins) in RS is less clear.

\section{Sodium Retention/Fluid Overload}

Sodium retention and expansion of extracellular water that may occur in the early phases of RS can lead to fluid overload, pulmonary edema, and cardiac decompensation. ${ }^{53,54}$ This may be especially devastating to patients at risk for RS (eg, patients with severe malnutrition) because they may have reduced cardiac mass and function. ${ }^{53,55}$ Fluid and sodium restriction are indicated when initiating nutrition support in patients at risk for RS. Patients should be monitored closely for signs of fluid accumulation and overload.

\section{Prevention}

Clearly, preventing RS is the primary goal when initiating nutrition support in severely malnourished and cachectic patients. There are several key steps that clinicians should take to avoid RS and the morbidity and mortality associated with RS. It is essential to first identify patients who are at risk for RS before initiating nutrition support (Table 2). Regardless of the method used to estimate caloric goals (eg, Harris-Benedict equation, $\mathrm{kcal} / \mathrm{kg}$, etc), it is essential to avoid overfeeding. The minimum glucose requirement for a $70-\mathrm{kg}$ adult to suppress gluconeogenesis, spare proteins, and supply fuel to the central nervous system is approximately 100$150 \mathrm{~g} /$ day. $^{3}$ A reasonable goal for protein intake in adults is approximately $1.5 \mathrm{~g} / \mathrm{kg} /$ day, although some patients may have increased (eg, severe trauma, severe burns, continuous renal replacement therapy, hepatic dysfunction or cirrhosis with encephalopathy [CRRT]) or decreased requirements (eg, renal failure with uremia).

When initiating nutrition support in patients at risk for $\mathrm{RS}$, the rule of thumb is to "start low and go slow." Nutrition support should be initiated cautiously (eg, approximately $25 \%$ of estimated goal needs on day 1), and gradually increased to goal over the course of 3-5 days. Any electrolyte abnormalities (especially hypophosphatemia, hypokalemia, and hypomagnesemia) should be corrected before nutrition support is initiated. Providing empiric

Table 2

Identification of patients at risk for refeeding syndrome

\section{Anorexia nervosa}

Classic marasmus/kwashiorkor

Residents admitted from skilled nursing facilities

Unfed for 7-10 days with evidence of stress/depletion

Chronic diseases causing undernutrition (eg, cancer or cardiac cachexia, chronic obstructive pulmonary disease, cirrhosis)

History of excessive alcohol intake

Morbid obesity with massive weight loss 
electrolyte supplementation (in patients with normal renal function) before and during nutrition support is advisable. Increasing total caloric load may decrease serum phosphorus concentration, and it is necessary to provide a minimum of approximately 10-15 mmol of phosphate per $1000 \mathrm{kcal}$ to maintain normal serum concentrations (in patients with normal renal function). ${ }^{11}$ Patients with severe malnutrition, critical illness, severe trauma, and burns will also likely have a depletion of total body phosphorus (even if serum concentrations are normal), and their phosphate requirements will be higher. The same may be true for potassium and magnesium in these patients as well. After nutrition support is initiated and titrated upward, electrolytes should be supplemented according to serum electrolyte concentrations and response to therapy.

Because patients at risk for RS may also have diminished cardiac reserve and can develop fluid overload, fluid and sodium should be minimized during the first few days of nutrition support (eg, sodium $\leq 20 \mathrm{mEq} /$ day, total fluid of $\leq 1000$ $\mathrm{mL} /$ day) ${ }^{56}$ Patients should gain no more than $1 \mathrm{~kg}$ per week during repletion. Any weight gain $>1$ $\mathrm{kg} / \mathrm{w}$ eek would likely be attributed to fluid retention. ${ }^{56}$

Vitamin supplementation should also be provided. Parenteral multivitamin preparations provide daily requirements as recommended by the American Medical Association. ${ }^{57}$ These preparations contain $3 \mathrm{mg}$ or $6 \mathrm{mg}$ of thiamine daily. However, thiamine requirements are increased in cachectic patients, and additional supplementation has been suggested. ${ }^{58}$ Supplemental thiamine at $50-100 \mathrm{mg} /$ day IV, or $100 \mathrm{mg}$ PO for 5-7 days should be provided to patients at risk for thiamine deficiency or RS. Most reports have focused on thiamine deficiency, but other vitamins may also be deficient in the malnourished patient. Although the importance of other vitamin deficiencies in RS is less clear, administering supplemental vitamins (especially folic acid) to patients at risk for $\mathrm{RS}$ is a reasonable approach. In addition to thiamine, 1 $\mathrm{mg} /$ day folic acid may also be provided for 5-7 days. Alternatively, providing a supplemental multivitamin PO daily in addition to EN for 5-7 days is reasonable. These steps can be done safely and inexpensively and may prevent patient morbidity.

Patients should be monitored closely for signs and symptoms of RS. Vital signs, including heart rate, blood pressure, respiratory rate, mental status, and neurologic function, should be monitored routinely, especially during the first several days of nutrition support until goal is reached. Finger pulse oximetry should be used if available, and patients should also be monitored for any electrocardiographic changes if possible. In addition, patients should be evaluated for any neuromuscular signs and symptoms during daily physical examinations. Patients should also be assessed for fluid balance, signs of edema, fluid overload, and weighed on a regular basis.

\section{Treatment}

Treatment of RS includes supportive care and treatment of any electrolyte disorders. If the patient exhibits any signs or symptoms consistent with RS, nutrition support should be interrupted immediately. Dextrose $10 \%$ in water can be initiated instead at the same rate to avoid rebound hypoglycemia if desired. A "stat" laboratory assessment should be made to evaluate serum electrolyte and glucose levels. If the patient exhibits any neurologic changes (eg, mental status changes, encephalopathy), a single dose of IV thiamine $100 \mathrm{mg}$ should be given. If respiratory distress or other respiratory symptoms are present, supplemental oxygen should be provided, and an arterial blood gas obtained. Cardiovascular changes should be addressed and treated immediately. Any evidence of fluid overload should also be treated appropriately (eg, diuretic therapy).

The following sections provide suggestions for treatment of specific electrolyte abnormalities. We would recommend administering $\leq 50 \%$ of the initial empiric doses of electrolytes (phosphate, potassium, and magnesium) in patients with impaired renal function (eg, creatinine clearance $<50 \mathrm{~mL} / \mathrm{min}$, serum creatinine $\geq 2 \mathrm{mg} / \mathrm{dL}$, patients who are oliguric [urine output $<400 \mathrm{~mL} /$ day] or anuric [urine output $<100 \mathrm{~mL} /$ day]) who are not treated with CRRT. In addition, when using weight-based dosing, there are no definitive data or recommendations for "adjusting" weight in patients who are significantly obese. There is also debate on when clinicians should use an "adjusted" body weight (eg, using a percentage above IBW or according to body mass index $[\mathrm{BMI}])$. Adipose tissue is estimated to be composed of approximately $10 \%-30 \%$ water, ${ }^{59-63}$ and total body water in men is slightly higher that that in women. Often in clinical practice, an "adjustment" of 25\%-40\% of the difference between actual weight and IBW is added to the IBW to determine the "adjusted" body weight or dosing weight.

Even though this practice is controversial, adjusting body weight in obese patients may minimize the risk of overdosing and complications.

\section{Treatment of Hypophosphatemia}

Treatment of hypophosphatemia depends on the magnitude of hypophosphatemia, whether or not the patient is symptomatic, and the route of administration that is available (ie, enteral or parenteral). Patients with mild hypophosphatemia who are asymptomatic and have a functioning gastrointestinal tract may be treated with oral phosphates. However, oral absorption can be unreliable, and oral phosphate products may cause diarrhea. Asymptomatic patients with moderate to severe hypophosphatemia who cannot receive oral medications and patients who are symptomatic should receive IV phosphate supplementation. Phosphate dosing is largely empiric because serum concentrations may 
Table 3

Treatment of hypophosphatemia ${ }^{64-70 *}$

\begin{tabular}{lc} 
Degree of hypophosphatemia & IV phosphate replacement dosage ${ }^{*} \dagger$ \\
\hline $\begin{array}{l}2.3-2.7 \mathrm{mg} / \mathrm{dL} \text { (mild } \\
\text { hypophosphatemia, }\end{array}$ & $0.08-0.16 \mathrm{mmol} / \mathrm{kg}$ \\
asymptomatic) & \\
$\begin{array}{l}1.5-2.2 \mathrm{mg} / \mathrm{dL} \text { (moderate } \\
\text { hypophosphatemia, }\end{array}$ & $0.16-0.32 \mathrm{mmol} / \mathrm{kg}$ \\
asymptomatic) & \\
$<1.5 \mathrm{mg} / \mathrm{dL}$ (Severe & $0.32-0.64 \mathrm{mmol} / \mathrm{kg}$ \\
symptomatic \\
hypophosphatemia)
\end{tabular}

* In patients with normal renal function; patients with renal insufficiency should receive $\leq 50 \%$ of the initial empiric dose. Maximum infusion rate $=7 \mathrm{mmol}$ phosphate $/ \mathrm{h}$.

†We suggest using adjusted body weight (AdjBW) in patients who are significantly obese (weight $>130 \%$ of IBW or BMI $\geq 30 \mathrm{~kg} / \mathrm{m}^{2}$ ): $A d j B W(m e n)=([\mathrm{wt}(\mathrm{kg})-\mathrm{IBW}(\mathrm{kg})] \times 0.3)+\mathrm{IBW} ; \mathrm{AdjBW}$ $($ women $)=([\mathrm{wt}(\mathrm{kg})-\mathrm{IBW}(\mathrm{kg})] \times 0.25)+\mathrm{IBW}$.

not correlate with total body phosphorus stores. Suggested IV phosphate dosing is provided in Table $3 .{ }^{64-70}$ We recommend providing $\leq 50 \%$ of the initial empiric phosphate dose in patients with impaired renal function who are not treated with CRRT. Patients treated with CRRT have continuous phosphorus clearance and may require higher initial doses, depending on the degree of hypophosphatemia and whether or not phosphate is used in the dialysate/replacement fluid. Further phosphate supplementation should be guided by clinical response to the initial dose.

IV phosphate formulations are available as potassium or sodium salts. One mmol of potassium phosphate contains $1.47 \mathrm{mEq}$ of potassium, and $1 \mathrm{mmol}$ of sodium phosphate contains $1.33 \mathrm{mEq}$ of sodium. Potassium phosphate can be used in patients with simultaneous hypokalemia; otherwise sodium phosphate should be used. Total phosphate dose should be infused over 4-6 hours to minimize adverse effects (eg, thrombophlebitis from potassium phosphate) and to reduce the risk of calcium-phosphate precipitation. Doses can be infused up to a rate of 7 mmol of phosphate per hour (or about $10 \mathrm{mEq}$ of potassium per hour). ${ }^{69,70}$ Serum phosphorus concentration should be checked 2-4 hours after a dose and additional phosphate supplementation provided until the patient is asymptomatic or the serum phosphorus concentration is in the normal range. Serum phosphorus concentration should be monitored at least daily for the first week of nutrition support. More frequent monitoring may be indicated in the first several days of nutrition support, especially in patients who manifest signs or symptoms of hypophosphatemia.

\section{Treatment of Hypokalemia}

Hypokalemia can be treated with potassium supplementation via the oral or IV route. The IV route should be used when treating patients with symptomatic or severe hypokalemia (eg, serum potassium concentration $<2.5 \mathrm{mEq} / \mathrm{L}$ ), or when the gastrointestinal tract cannot be used. Dosing of potassium is largely empiric and based on clinical response and serum concentrations. Suggestions for potassium dosing are provided in Table $4 .^{71-73}$ We would also recommend that patients with impaired renal function who are not being treated with CRRT receive $\leq 50 \%$ of the recommended initial dose. Patients receiving CRRT may have higher clearance of potassium and require higher initial doses. Serum potassium concentration should be checked within 1-4 hours after a dose, and multiple doses of potassium may be required for full repletion. Potassium can be safely administered in adult patients at rates of $10-20 \mathrm{mEq} / \mathrm{h}$. Rates $>20 \mathrm{mEq} / \mathrm{h}$ are rarely needed, except in emergent situations. Patients should receive potassium via a central venous catheter and should have continuous cardiac monitoring for infusion rates $>10 \mathrm{mEq} / \mathrm{h}$. Potassium should never be given as a rapid infusion to avoid serious or fatal consequences. Potassium concentration in solutions for continuous infusion via a peripheral vein should be limited to $80 \mathrm{mEq} / \mathrm{L}$, and up to $120 \mathrm{mEq} / \mathrm{L}$ can be used for infusion via a central vein. These standard recommendations are provided for safety, although

Table 4

Treatment of hypokalemia ${ }^{71-73 *}$

Degree of hypokalemia $\quad \begin{gathered}\text { IV potassium } \\ \text { replacement dosage* }\end{gathered} \quad$ Rate of IV infusiont $\quad$ Maximum concentration

Serum potassium concentration $=2.5-3.4 \mathrm{mEq} / \mathrm{L}$

(mild to moderate hypokalemia, asymptomatic)

$20-40 \mathrm{mEq}$

$10-20 \mathrm{mEq}$ potassium $/ \mathrm{h} ;$ maximum of $40 \mathrm{mEq}$ potassium/h
$80 \mathrm{mEq} / \mathrm{L}$ via a peripheral vein; up to $120 \mathrm{mEq} / \mathrm{L}$ via a central vein ladmixed in $0.9 \%$ sodium chloride in water, or $0.45 \%$ sodium chloride in water)

Serum potassium concentration $<2.5 \mathrm{mEq} / \mathrm{L}$, or if $\quad 40-80 \mathrm{mEq}$ symptomatic (severe symptomatic hypokalemia)

* In patients with normal renal function; patients with renal insufficiency should receive $\leq 50 \%$ of the initial empiric dose.

†Continuous cardiac monitoring and infusion via a central venous catheter are recommended for infusion rates $>10 \mathrm{mEq}$ potassium per hour. 
individual recommendations and practices may vary slightly.

Oral potassium supplementation can be provided, but oral supplements can cause gastrointestinal side effects (eg, cramping, diarrhea), and oral liquid formulations have an unpleasant taste. We recommend an oral potassium dose of $20-40 \mathrm{mEq}$, or a total dose of 40-100 $\mathrm{mEq} /$ day as an initial regimen to correct hypokalemia. Oral doses should be divided into 2-4 doses to minimize gastrointestinal side effects.

Serum potassium concentration should be monitored at least daily during the first several days of nutrition support. Because hypomagnesemia may cause refractory hypokalemia, magnesium deficiency should be corrected, along with potassium supplementation, in order to facilitate the correction of hypokalemia. ${ }^{74}$

\section{Treatment of Hypomagnesemia}

Magnesium deficiency has been associated with a total body magnesium deficiency of $1-2 \mathrm{mEq} / \mathrm{kg}$. ${ }^{75}$ IV treatment of hypomagnesemia should be the preferred route in patients at risk for RS if symptomatic and when the gastrointestinal tract cannot be used. Oral magnesium supplements have a slow onset and are associated with diarrhea and gastrointestinal intolerance. Suggestions for empiric IV dosing of magnesium (for patients with normal renal function) are listed in Table $5 .^{39,41,75-83}$ Because magnesium distribution and equilibration between serum and intracellular spaces and tissues are slow $^{32,84}$ but renal elimination is rapid (with up to $50 \%$ of an IV dose of magnesium excreted in the urine), ${ }^{31,32,75-77,80,82}$ infusion time of IV magnesium is important. In nonemergent situations, we recommend infusing doses of $\leq 6 \mathrm{~g}$ of magnesium sulfate over 6-12 hours and infusing higher doses over 12-24 hours, with a maximum of $1 \mathrm{~g}$ magnesium sulfate $(\sim 8.1 \mathrm{mEq}$ elemental magnesium) over 1 hour. More rapid administration rates may simply increase urinary loss of magnesium. Additional supplementation may be required, and total repletion of magnesium may take several days. Severe symptomatic hypomagnesemia may require more aggressive dosing in the acute setting (eg, $4 \mathrm{~g}$ magnesium sulfate [ $\sim 32 \mathrm{mEq}$ elemental magnesium] over 4-5 minutes has been used in patients with preeclampsia or eclampsia). ${ }^{75,80}$

For patients with impaired renal function, we recommend using $\leq 50 \%$ of the suggested empiric magnesium dose. The patient must be monitored carefully, especially when magnesium doses approach the maximum recommendations (approximately $12 \mathrm{~g}$ magnesium sulfate [ $\sim 97 \mathrm{mEq}$ elemental magnesium] over 12 hours). ${ }^{75}$ Serum magnesium concentration should be checked approximately 12-24 hours after magnesium repletion. Serum magnesium concentrations can be monitored more frequently in the acute setting; however, because of the slow magnesium equilibrium, ${ }^{32,84}$ serum magnesium concentration can seem artificially high if measured too soon after a dose. ${ }^{79}$ Serum concentrations should be monitored at least once daily during the first several days of nutrition support in patients at risk for $\mathrm{RS}$.

\section{Restarting Nutrition Support}

If a patient manifests signs and symptoms of RS, nutrition support should be restarted with great caution. All electrolyte abnormalities should be adequately treated and supplemental electrolytes provided in the nutrition formulation above what was previously provided when RS symptoms developed. Multivitamins should also be supplemented as described earlier. The patient should be free of symptoms and stable before restarting nutrition support. We suggest initiating nutrition support at $\leq 50 \%$ of the previous rate when symptoms develop, and advance nutrition to goal cautiously over at least 4-5 days. The patient should be monitored closely for further signs and symptoms of RS.

Table 5

Treatment of hypomagnesemia $39,41,75-83$ *

Degree of hypomagnesemia

Serum magnesium concentration $=1-1.5 \mathrm{mg} / \mathrm{dL}$

(mild to moderate hypomagnesemia, asymptomatic)

Serum magnesium concentration $<1 \mathrm{mg} / \mathrm{dL}$ (severe

symptomatic hypomagnesemia)

Rate of IV infusion
IV magnesium replacement dosage ${ }^{*} \dagger$

1-4 g magnesium sulfate (8-32 mEq magnesium), up to 1 $\mathrm{mEq} / \mathrm{kg} \ddagger$

4-8 g magnesium sulfate (32-64 mEq magnesium), up to 1.5 $\mathrm{mEq} / \mathrm{kg} \ddagger$

Maximum of $1 \mathrm{~g}$ magnesium sulfate $/ \mathrm{h}$ ( $8 \mathrm{mEq}$ magnesium $/ \mathrm{h}$ ), up to $12 \mathrm{~g}$ magnesium sulfate

(97 mEq magnesium) over $12 \mathrm{~h}$ if asymptomatic; up to 32 mEq magnesium over 4-5 min in severe symptomatic hypomagnesemia

\footnotetext{
*In patients with normal renal function; patients with renal insufficiency should receive $\leq 50 \%$ of the initial empiric dose. †We suggest using adjusted body weight (AdjBW) in patients who are significantly obese (weight $>130 \%$ of $\mathrm{IBW}$ or $\mathrm{BMI} \geq 30 \mathrm{~kg} / \mathrm{m}^{2}$ ): $A d j B W($ men $)=([\mathrm{wt}(\mathrm{kg})-\mathrm{IBW}(\mathrm{kg})] \times 0.3)+\mathrm{IBW} ; \mathrm{AdjBW}($ women $)=([\mathrm{wt}(\mathrm{kg})-\mathrm{IBW}(\mathrm{kg})] \times 0.25)+\mathrm{IBW}$.

‡One gram magnesium sulfate $=8.1 \mathrm{mEq}$ magnesium .
} 


\section{Summary}

$\mathrm{RS}$ is a serious condition that can develop in underweight, severely malnourished, or starved individuals during nutrition repletion. RS involves significant electrolyte, fluid, and vitamin abnormalities that can lead to significant morbidity and mortality. Clinicians should be aware of RS, identify patients at risk of developing RS, and most importantly take steps to prevent RS. Patients who develop signs and symptoms of RS require aggressive electrolyte supplementation, vitamin supplementation, and supportive care, and nutrition support should be restarted with great caution.

\section{References}

1. Keys A, Brozek J, Henschel A, Mickelson O, Taylor HD, eds. The Biology of Human Starvation, Vols. 1, 2. Minneapolis, MN: University of Minnesota Press; 1950.

2. Weinsier RL, Krumdieck CL. Death resulting from overzealous total parenteral nutrition: the refeeding syndrome revisited. Am J Clin Nutr. 1980;34:393-399.

3. Cahill GF. Starvation in man. N Engl J Med. 1970;282:668-675.

4. DeFronzo RA, Cooke CR, Andres R, Faloona GR, Davis PJ. The effect of insulin on renal handling of sodium, potassium, calcium, and phosphate in man. $J$ Clin Invest. 1975;55:845-855.

5. Guirao X, Franch G, Gil MJ, Garcia-Domingo MI, Girvent M, Sitges-Serra A. Extracellular volume, nutritional status, and refeeding changes. Nutrition. 1994;10:558-561.

6. Van Way CW, Longoria M, Sacks GS. Do surgeons need to worry about vitamin deficiencies? Nutr Clin Pract. 2001;16(suppl):S5S7.

7. Travis SF, Sugerman HJ, Ruberg RL, et al. Alterations of red-cell glycolytic intermediates and oxygen transport as a consequence of hypophosphatemia in patients receiving intravenous hyperalimentation. N Engl J Med. 1971;285:763-768.

8. Silvis SE, Paragas PD. Paresthesias, weakness, seizures, and hypophosphatemia in patients receiving hyperalimentation. Gastroenterology. 1972;62:513-520.

9. Sand DW, Pastore RA. Paresthesias and hypophosphatemia occurring with parenteral alimentation. Am J Dig Dis. 1973;18: 709-713.

10. Furlan AJ, Hanson M, Cooperman A, Farmer RG. Acute areflexic paralysis: association with hyperalimentation and hypophosphatemia. Arch Neurol. 1975;32:706-707.

11. Sheldon GF, Grzyb S. Phosphate depletion and repletion: relation to parenteral nutrition and oxygen transport. Ann Surg. 1975; 182:683-689.

12. Baughman FA Jr, Papp JP. Wernicke's encephalopathy with intravenous hyperalimentation: remarks on similarities between Wernicke's encephalopathy and the phosphate depletion syndrome. Mt Sinai J Med. 1976;43:48-52.

13. Silvis SE, DiBartolomeo AG, Aaker HM. Hypophosphatemia and neurological changes secondary to oral caloric intake. Am J Gastroentenerol. 1980;73:215-222.

14. Youssef HAE. Hypophosphatemic respiratory failure complicating PN: an iatrogenic potentially lethal hazard [letter]. Anesthesiology. 1982;57:246.

15. Hayek ME, Eisenberg PG. Severe hypophosphatemia following the institution of enteral feedings. Arch Surg. 1989;124:13251328.

16. Vanneste J, Hage J. Acute severe hypophosphatemia mimicking Wernicke's encephalopathy [letter]. Lancet. 1986;1:44.

17. Mattioli S, Miglioli M, Montagna P, Lerro MF, Pilotti V, Gozzetti G. Wernicke's encephalopathy during PN: observation in one case. JPEN J Parenter Enteral Nutr. 1988;12:626-627.

18. O'Connor LR, Wheeler WS, Bethune JE. Effect of hypophosphatemia on myocardial performance in man. $N$ Engl $J$ Med. 1977;297:901-903.
19. Newman JH, Neff TA, Ziporin P. Acute respiratory failure associated with hypophosphatemia. N Engl J Med. 1977;296:11011103.

20. Aubier M, Murciano D, Lecocguic Y, et al. Effect of hypophosphatemia on diaphragmatic contractility in patients with acute respiratory failure. $N$ Engl J Med. 1985;313:420-424.

21. Benesch R, Benesch RE. The effect of organic phosphates from the human erythrocyte on the allosteric properties of hemoglobin. Biochem Biophys Res Commun. 1967;26:162-167.

22. Lichtman MA, Miller DR, Cohen J, Waterhouse C. Reduced red cell glycolysis, 2,3-diphosphoglycerate and adenosine triphosphate concentration, and increased hemoglobin-oxygen affinity caused by hypophosphatemia. Ann Intern Med. 1971;74:562-568.

23. Thomas HM, Lefrak SS, Irwin RS, Fritts Jr HW, Caldwell PRB. The oxyhemoglobin dissociation curve in health and disease: role of 2,3-diphosphoglycerate. Am J Med. 1974;57:331-348.

24. Mandal AK. Hypokalemia and hyperkalemia. Med Clin North Am. 1997;81:611-639.

25. Halperin ML, Kamel KS. Potassium. Lancet. 1998;352:135-140.

26. Freedman BI, Burkart JM. Hypokalemia. Crit Care Clin. 1991;7: 143-153.

27. Brophy DF, Gehr TWB. Disorders of potassium and magnesium homeostasis. In: Dipiro JT, Talbert RL, Yee GC, et al, eds. Pharmacotherapy: A Pathophysiologic Approach. $5^{\text {th }}$ ed. New York, NY: McGraw-Hill; 2002:981-993.

28. Gennari FJ. Hypokalemia. N Engl J Med. 1998;339:451-458.

29. Agarwal A, Wingo CS. Treatment of hypokalemia. N Engl J Med. 1999;340:154-155.

30. Wacker WEC, Parisi AF. Magnesium metabolism. N Engl J Med. 1968;278:658-663, 712-717, 772-776.

31. Graber TW, Yee AS, Baker FJ. Magnesium: physiology, clinical disorders, and therapy. Ann Emerg Med. 1981;10:49-57.

32. Reinhart RA. Magnesium metabolism: a review with special reference to the relationship between intracellular content and serum levels. Arch Intern Med. 1988;148:2415-2420.

33. Wacker WE. The biochemistry of magnesium. Ann N Y Acad Sci. 1969;162:717-726

34. Reinhart RA, Desbiens NA. Hypomagnesemia in patients entering the ICU. Crit Care Med. 1985;13:506-507.

35. Ryzen E, Wagers PW, Singer FR, Rude RK. Magnesium deficiency in a medical ICU population. Crit Care Med. 1985;13:19-21.

36. Chernow B, Bamberger S, Stoiko M, et al. Hypomagnesemia in patients in postoperative intensive care. Chest. 1989;95:391-397.

37. Frankel H, Haskell R, Lee SY, et al. Hypomagnesemia in trauma patients. World J Surg. 1999;23:966-969.

38. Rubiez GJ, Thill-Baharozian M, Hardie D, Carlson RW. Association of hypomagnesemia and mortality in acutely ill medical patients. Crit Care Med. 1993;21:203-209.

39. Ceremuzynski L, Hao NV. Ventricular arrhythmias late after myocardial infarction are related to hypomagnesemia and magnesium loss: preliminary trial of corrective therapy. Clin Cardiol. 1993;16:493-496.

40. Kingston ME, Al-Siba'I MB, Skooge WC. Clinical manifestations of hypomagnesemia. Crit Care Med. 1986;14:950-954.

41. Salem M, Munoz R, Chernow B. Hypomagnesemia in critical illness: a common and clinically important problem. Crit Care Clin. 1991;7:225-252.

42. Seelig MS. Electrographic patterns of magnesium depletion appearing in alcoholic heart disease. Ann N Y Acad Sci. 1969;162: 906-917.

43. Skou JC. Further investigations on a $\mathrm{Mg}^{++}+\mathrm{Na}^{+}$-activated adenosine triphosphate, possibly related to the active, linked transport of $\mathrm{Na}^{+}$and $\mathrm{K}^{+}$across the nerve membrane. Biochem Biophys Acta. 1960;42:6-23.

44. Weisinger JR, Bellorin-Font E. Magnesium and phosphorous. Lancet. 1998;352:391-396.

45. Anast CS, Winnacker JL, Forte LR, Burns TW. Impaired release of parathyroid hormone in magnesium deficiency. J Clin Endocrinol Metab. 1976;42:707-717.

46. Fatemi G, Ryzen E, Flores J, Endres DB, Rude RK. Effect of experimental human magnesium depletion on parathyroid hormone secretion and 1,25-dihydroxyvitamin D metabolism. J Clin Endocrinol Metab. 1991;73:1067-1072. 
47. Reuler JB, Girard DE, Cooney TG. Wernicke's encephalopathy. $N$ Engl J Med. 1985;312:1035-1039.

48. Romanski SA, McMahon MM. Metabolic acidosis and thiamine deficiency. Mayo Clin Proc. 1999;74:259-263.

49. Kitamura K, Takahashi T, Tanaka H, et al. Two cases of thiamine deficiency-induced lactic acidosis during PN. Tohoku J Exp Med. 1993;171:129-133.

50. Barrett TG, Forsyth JM, Nathavitharana KA, Booth IW. Potentially lethal thiamine deficiency complicating parenteral nutrition in children. Lancet. 1993;341:901-902.

51. Centers for Disease Control and Prevention. Deaths associated with thiamine-deficient PN. MMWR Morb Mortal Wkly Rep. 1989;38:43-46.

52. Centers for Disease Control and Prevention. Lactic acidosis traced to thiamine deficiency related to nationwide shortage of multivitamins for PN. MMWR Morb Mortal Wkly Rep. 1997;46: $523-528$.

53. Heymsfield SB, Bethel RA, Ansley JD, Gibbs DM, Felner JM, Nutter DO. Cardiac abnormalities in cachectic patients before and during nutritional repletion. Am Heart J. 1978;95:584-594.

54. Huang YL, Fang CT, Tseng MC, Lee YJ, Lee MB. Life-threatening refeeding syndrome in a severely malnourished anorexia nervosa patient. J Formos Med Assoc. 2001;100:343-346.

55. Gottdiener JS, Gross HA, Henry WL, Borer JS, Ebert MH. Effects of self-induced starvation on cardiac size and function in anorexia nervosa. Circulation. 1978;58:425-433.

56. Apovian CM, McMahon MM, Bistran BR. Guidelines for refeeding the marasmic patient. Crit Care Med. 1990;18:1030-1033.

57. Nutrition Advisory Group, AMA Department of Foods and Nutrition. Multivitamin preparations for parenteral use, 1975. JPEN J Parenter Enteral Nutr. 1979;3:258-262.

58. Brooks MJ, Melnik G. The refeeding syndrome: an approach to understanding its complications and preventing its occurrence. Pharmacotherapy. 1995;15:713-726.

59. Hankin ME, Munz K, Steinbeck AW. Total body water content in normal and grossly obese women. Med J Aust. 1976;2:533-537.

60. Watson PE, Watson ID, Batt RD. Total body water volumes for adult males and females estimated from simple anthropometric measurements. Am J Clin Nutr. 1980;33:27-39.

61. Schoeller DA, van Santen E, Peterson DW, et al. Total body water measurement in humans with ${ }^{18} \mathrm{O}$ and ${ }^{2} \mathrm{H}$ labeled water. $A m J$ Clin Nutr. 1980;33:2686-2693.

62. Webster JD, Hesp R, Garrow JS. The composition of excess weight in obese women estimated by body density, total body water and total body potassium. Hum Nutr Clin Nutr. 1984;38: 299-306.

63. Foster GD, Wadden TA, Mullen JL, et al. Resting energy expenditure, body composition, and excess weight in the obese. Metabolism. 1988;37:467-472.

64. Lentz RD, Brown DM, Kjellstrand CM. Treatment of severe hypophosphatemia. Ann Intern Med. 1978;89:941-944.

65. Vannatta JB, Whang R, Papper S. Efficacy of intravenous phosphorous therapy in the severely hypophosphatemic patient. Arch Intern Med. 1981;141:885-887.
66. Andress DL, Vannatta JB, Whang R. Treatment of refractory hypophosphatemia. South Med J. 1982;75:766-767.

67. Vannatta JB, Andress DL, Whang R, Papper S. High-dose intravenous phosphorus therapy for severe complicated hypophosphatemia. South Med J. 1983;76:1424-1426.

68. Kingston M, Al-Siba'i MB. Treatment of severe hypophosphatemia. Crit Care Med. 1985;13:16-18.

69. Rosen GH, Boullata JI, O'Rangers EA, Enow NB, Shin B. Intravenous phosphate repletion regimen for critically ill patients with moderate hypophosphatemia. Crit Care Med. 1995;23:1204-1210.

70. Clark CL, Sacks GS, Dickerson RN, Kudsk KA, Brown RO. Treatment of hypophosphatemia in patients receiving specialized nutrition support using a graduated dosing scheme: results from a prospective clinical trial. Crit Care Med. 1995;23:1504-1511.

71. Kruse JA, Carlson RW. Rapid correction of hypokalemia using concentrated intravenous potassium chloride infusions. Arch Intern Med. 1990;150:613-617.

72. Hamill RJ, Robinson LM, Wexler HR, Moote C. Efficacy and safety of potassium infusion therapy in hypokalemic critically ill patients. Crit Care Med. 1991;19:694-699.

73. Kruse JA, Clark VL, Carlson RW, Geheb MA. Concentrated potassium chloride infusions in critically ill patients with hypokalemia. J Clin Pharmacol. 1994;34:1077-1082.

74. Ryan MP. Interrelationships of magnesium and potassium homeostasis. Mineral Electrolyte Metab. 1993;19:290-295.

75. Flink EB. Therapy of magnesium deficiency. Ann N Y Acad Sci. 1969;162:901-905.

76. Heaton FW. The kidney and magnesium homeostasis. Ann N Y Acad Sci. 1969;162:775-785.

77. Martin HE. Clinical magnesium deficiency. Ann N Y Acad Sci. 1969;162:891-900

78. Dickerson RN, Brown RO. Hypomagnesemia in hospitalized patients receiving nutritional support. Heart Lung. 1985;14:561569

79. Rasmussen HS, McNair P, Norregard P, Backer V, Lindeneg O, Balslev S. Intravenous magnesium in acute myocardial infarction. Lancet. 1986;1:234-236.

80. Oster JR, Epstein M. Management of magnesium depletion. Am $J$ Nephrol. 1988;8:349-354

81. Sacks GS, Brown RO, Dickerson RN, et al. Mononuclear blood cell magnesium content and serum magnesium concentration in critically ill hypomagnesemic patients after replacement therapy. Nutrition. 1997;13:303-307.

82. Hebert P, Mehta N, Wang J, Hindmarsh T, Jones G, Cardinal P. Functional magnesium deficiency in critically ill patients identified using a magnesium-loading test. Crit Care Med. 1997;25: $749-755$.

83. Huycke MM, Naguib MT, Stroemmel MM, et al. A double-blind placebo-controlled crossover trial of intravenous magnesium sulfate for foscarnet-induced ionized hypocalcemia and hypomagnesemia in patients with AIDS and cytomegalovirus infection. Antimicrob Agents Chemother. 2000;44:2143-2148.

84. Barnes BA. Magnesium conservation: a study of surgical patients. Ann N Y Acad Sci. 1969;162:786-801. 